\title{
Label-free electrochemical biosensing of small-molecule inhibition on O- GlcNAc glycosylation
}

\author{
Yu Yang ${ }^{\mathrm{a}, *}$, Yuxin $\mathrm{Gu}^{\mathrm{a}, \mathrm{b}}$, Bin Wan ${ }^{\mathrm{a}, \mathrm{b}}$, Xiaomin Ren ${ }^{\mathrm{a}}$, Liang-Hong Guo ${ }^{\mathrm{a}, \mathrm{b}, \mathrm{c}, * * *}$ \\ a State Key Laboratory of Environmental Chemistry and Ecotoxicology, Research Center for Eco-Environmental Sciences, Chinese Academy of Sciences, 18 \\ Shuangqing Road, P.O. Box 2871, Beijing 100085, China \\ ${ }^{\mathrm{b}}$ University of Chinese Academy of Sciences, Beijing 100049, China \\ c Institute of Environment and Health, Jianghan University, Wuhan 430056, China
}

\section{A R T I C L E I N F O}

Keywords:

Electrochemical

Tyrosine

O-GlcNAc glycosylation

Inhibition

Indium tin oxide

\begin{abstract}
A B S T R A C T
O-linked N-acetylglucosamine (O-GlcNAc) transferase (OGT) plays a critical role in modulating protein function in many cellular processes and human diseases such as Alzheimer's disease and type II diabetes, and has emerged as a promising new target. Specific inhibitors of OGT could be valuable tools to probe the biological functions of O-GlcNAcylation, but a lack of robust nonradiometric assay strategies to detect glycosylation, has impeded efforts to identify such compounds. Here we have developed a novel label-free electrochemical biosensor for the detection of peptide O-GlcNAcylation using protease-protection strategy and electrocatalytic oxidation of tyrosine mediated by osmium bipyridine as a signal reporter. There is a large difference in the abilities of proteolysis of the glycosylated and the unglycosylated peptides by protease, thus providing a sensing mechanism for OGT activity. When the O-GlcNAcylation is achieved, the glycosylated peptides cannot be cleaved by proteinase $\mathrm{K}$ and result in a high current response on indium tin oxide (ITO) electrode. However, when the O-GlcNAcylation is successfully inhibited using a small molecule, the unglycosylated peptides can be cleaved easily and lead to low current signal. Peptide O-GlcNAcylation reaction was performed in the presence of a well-defined small-molecule OGT inhibitor. The results indicated that the biosensor could be used to screen the OGT inhibitors effectively. Our label-free electrochemical method is a promising candidate for protein glycosylation pathway research in screening small-molecule inhibitors of OGT.
\end{abstract}

\section{Introduction}

O-GlcNAc transferase (OGT) is an essential mammalian enzyme that regulates numerous cellular processes through the attachment of O-linked $\mathrm{N}$-acetylglucosamine (O-GlcNAc) to serine and threonine residues of nuclear and cytoplasmic proteins (Hart et al., 2007; Vocadlo, 2012). Its targets include kinases, phosphatases, transcription factors, histones, and many other intracellular proteins (Levine et al., 2016). Also, many oncogenes or tumor suppressors are modified by OGlcNAc, such as c-Myc (Chou et al., 1995), retinoblastoma (Rb) (Wells et al., 2011), tumor suppressor hypermethylated in cancer 1 (HIC1) (Lefebvre et al., 2004), $\beta$-catenin (Sayat et al., 2008), and estrogen receptors (Cheng et al., 2001). O-GlcNAcylation plays critical roles in signal transduction (Zeidan et al., 2010), transcriptional control (Yang et al., 2002), cell cycle regulation (Slawson et al., 2005), protein degradation (Zhang et al., 2003), neurodegeneration (Gong et al.,
2005), and stress responses (Zachara et al., 2004). Aberrant OGT activity has been found to be involved in the pathogenesis mechanism of some diseases such as diabetes (Lehman et al., 2005), Alzheimer disease (Yuzwa et al., 2014) and cancer (Singh et al., 2015; Caldwell et al., 2010; Slawson et al., 2011), and OGT also has been proposed to be a therapeutic target for these diseases. The emerging roles of OGT in cellular processes as well as diseases make sensitive and easy-to-use tools that can detect and perturb the OGT function valuable.

Limited methods have been developed for the assay of OGT activity, including isotope labeling (Lubas et al., 2000), colorimetry (Wu et al., 2011), enzyme linked immunosorbent assay (ELISA) (Leavy et al., 2007) and fluorescence (Gross et al., 2005) etc. Among them, the conventional in vitro OGT activity assay utilizes a radiolabeled sugar substrate, such as uridine $5^{\prime}$-diphosphate (UDP) $-\left[{ }^{14} \mathrm{C}\right]$ GlcNAc or UDP$\left[{ }^{3} \mathrm{H}\right]$ GlcNAc (Lubas et al., 2000). This method measures OGT activity by quantifying radiolabeled GlcNAc incorporation into a protein

\footnotetext{
* Corresponding author.

** Corresponding author at: State Key Laboratory of Environmental Chemistry and Ecotoxicology, Research Center for Eco-Environmental Sciences, Chinese Academy of Sciences, 18 Shuangqing Road, P.O. Box 2871, Beijing 100085, China.

E-mail addresses: yuyang@rcees.ac.cn (Y. Yang), LHGuo@rcees.ac.cn (L.-H. Guo).
} 
substrate, but is high in cost and produces radiochemical waste. As an alternative to using radiochemicals, Wu et al. took advantage of specific phosphatases that can be added into glycosyltransferase reactions to quantitatively release inorganic phosphate from the leaving groups of glycosyltransferase reactions. The released phosphate group is then detected using colorimetric malachite-based reagents (Wu et al., 2011). Leavy et al. introduced an azido-enzyme-linked immunosorbent assay (azido-ELISA) method using the unnatural sugar donor, UDP-Nazidoacetyl glucosamine (UDPGlcNAz) and biotinylated peptide substrates (Leavy et al., 2007). In this method, a solution-phase enzymatic reaction is transferred into a microplate for subsequent solid-phase reactions, reducing the method's efficiency. Walker group introduced a ligand displacement OGT assay (Gross et al., 2005) and a proteaseprotection assay (Gross et al., 2008) respectively. The former method exploited fluorescence polarization using a fluorophore-containing UDP-GlcNAc analogue. The latter protease-protection assay exploited the fluorescence resonance energy transfer (FRET) phenomenon using specially designed, protease-specific peptide substrates. The peptide labeled with a FRET pair was subjected to glycosylation and then treated with a protease that cleaved the unglycosylated peptides to completion without affecting the glycosylated peptides (Gross et al., 2008). The resulting FRET signal was measured to determine the amount of proteolysis, which was related to the degree of peptide glycosylation. On this basis, they used this assay to screen the inhibitors for OGT. Nevertheless, these two fluorescence methods all involved complex chemical synthesis for fluorophore-labeled substances. Although some progress in the detection of OGT activity has been made, much more researches toward simple, cost-effective, labelfree methods are needed. Besides, there is a pressing demand for smallmolecule compounds to modulate the OGT activity in cells and in vivo, which is of prime interest for the better understanding of OGT biological implications, but there has no suitable means to investigate and screen such compounds.

In our work, further improvement in the rational design of the OGT activity assay is still necessary to obtain a simple, fast, label-free method with potential applications for the rapid identification of OGT inhibitors. Electrochemical strategy is proved to be a kind of promising way to achieve label-free assay of OGT activity due to the advantages of easy operation, simple instrument, low cost and high sensitivity. Here we devised an electrochemical biosensor for the determination of OGT activity and inhibition by combining a general protease-protection assay with tyrosine electroactive property (Scheme 1). In this approach, a peptide substrate containing tyrosine residues at C-terminal immobilized on the surface of ITO electrode was glycosylated by OGT and then treated with protease which could distinguish between glycosylated and non-glycosylated peptides. OGT catalyzed O-linked glycosylation of peptide and then the addition of a single sugar to a peptide would protect adjacent cleavage sites from proteolysis. The voltammetric current of the ITO electrode was detected in a solution containing electron mediator $\mathrm{Os}(\mathrm{bpy})_{3}{ }^{2+}\left(\mathrm{bpy}=2,2^{\prime}\right.$-bipyridine) for increased sensitivity. The resulting electro-catalyzed oxidation signal of tyrosine was measured, which was associated with the OGT activity. On this basis, we also explored the feasibility of the strategy by applying it to well-known OGT inhibitors. The biosensor should enable the determination of OGT activity and the identification of selective inhibitors for OGT.

\section{Materials and methods}

\subsection{Materials and instruments}

OGT and polypeptide N-acetylgalactosamine (GalNAc) transferase 2 (ppGalNAc-T2) were purchased from R\&D Systems Inc. OGT substrate peptide with the sequence of PGGSTPVSRANMKYYYYYY was synthesized from GL biochemical Ltd (Shanghai, China). (3glycidoxypropyl)-trimethoxysilane (GPTMS), proteinase K, uridine $5^{\prime}$ diphospho-N-acetylglucosamine sodium salt (UDP-GlcNAc), uridine 5'-diphospho-N-acetylgalactosamine disodium salt (UDP-GalNAc), alkaline phosphatase and alloxan were bought from Sigma Aldrich (St. Louis, MO, USA). Phenyl 5-chloro-2-oxo-3-hydrobenzoxazole-3-carboxylate (BZX) was provided by TimTec eChemStore (Newark, Delaware, USA). The metal complex $\mathrm{Os}(\mathrm{bpy})_{3} \mathrm{Cl}_{2}$ was prepared according to the procedures described elsewhere (Hamann et al., 2005). Peptide was dissolved in $20 \mathrm{mM}$ phosphate buffer ( $\mathrm{PB}, \mathrm{pH}$ 7.4). All reagents were of analytical reagent grade. Solutions were prepared in high-purity water from a Millipore milli-Q (Biocel) water purification system (Billerica, MA, USA). ITO conductive glass (film thickness: 900 $\pm 100 \AA$, conductivity: $19 \pm 2.1 \Omega / \square$ ) was obtained from Nanbo Corporation (Shenzhen, Guangdong, China). Cyclic voltammetry was performed on a CHI 660B electrochemistry analyzer from $\mathrm{CH}$ Instruments (Austin, TX) with a Pt counter electrode and an $\mathrm{Ag} / \mathrm{AgCl}$ reference electrode.

\subsection{Fabrication of electrochemical biosensor}

ITO conductive glass was cut into $5 \mathrm{~cm} \times 5 \mathrm{~cm}$ size slices. The slices were cleaned in an ultrasonic cleaner sequentially with each of the following solutions: household detergent in water $(15 \mathrm{~min})$, deionized
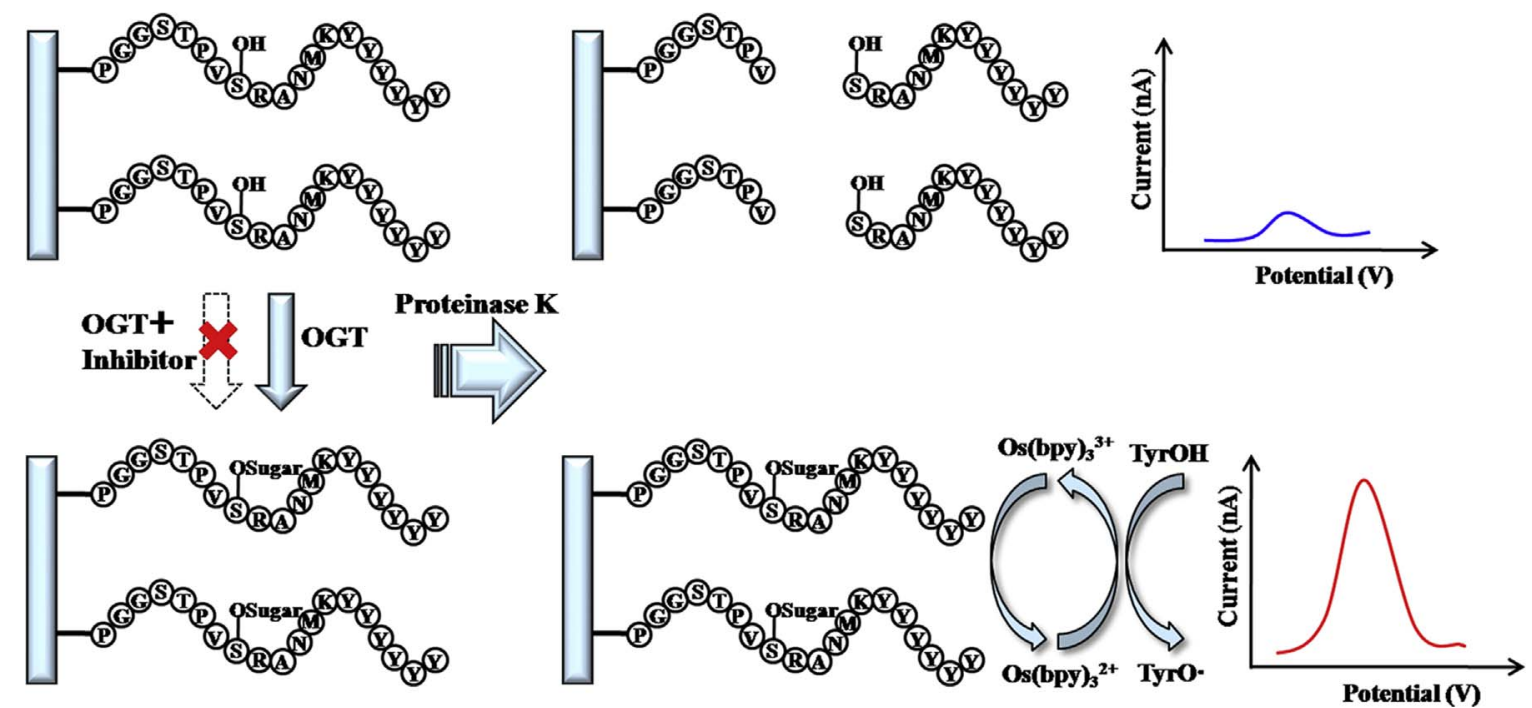

Scheme 1. Schematic representation of electrochemical sensing strategy for OGT activity detection using electro-catalyzed tyrosine oxidation as signal probe. 
water ( $2 \mathrm{~min}$, twice), acetone (5 $\mathrm{min}$ ), 2-propanol (5 $\mathrm{min}$ ), and deionized water $\left(10 \mathrm{~min}\right.$, twice). And then dried in an oven at $50^{\circ} \mathrm{C}$, followed by treating for $60 \mathrm{~s}$ with an Atmospheric Plasma Surface Treatment Systems CTD-1000z from Kulun Electronics Co., Ltd. (Nanjing, Jiangsu, China). The surface functionalization of ITO electrode was performed according to the following procedure (Yang et al., 2011). Firstly, the cleaned slices were immersed in a $1 \%$ (v/v) solution of GPTMS in dry toluene with shaking (40 rpm) at room temperature for $1 \mathrm{~h}$. Secondly, after the reaction, the slices were washed ultrasonically in dry toluene ( $5 \mathrm{~min}$, twice) and anhydrous ethanol (5 min, twice) to remove physically adsorbed GPTMS from the surface. Then, the modified slices were dried under a stream of nitrogen and cured at $115{ }^{\circ} \mathrm{C}$ for $20 \mathrm{~h}$. They were stored in a sealed box till use.

The salt-induced covalent immobilization of peptide on epoxysilane-activated ITO electrode was performed according to the following procedure. Firstly, epoxysilane-activated ITO slices were cut into $2.5 \mathrm{~cm} \times 0.5 \mathrm{~cm}$ electrodes, washed with purified water, and dried under a stream of nitrogen. Secondly, a $10 \mu \mathrm{L}$ peptide $\left(0.3 \mathrm{mg} \mathrm{mL}^{-1}, 2.0 \mathrm{M}\right.$ $\mathrm{PB}$ pH 7.4) solution was spread evenly on the bottom of each electrode over a $0.5 \mathrm{~cm} \times 0.5 \mathrm{~cm}$ area, and incubated in a moisturized container at $25^{\circ} \mathrm{C}$ for $24 \mathrm{~h}$. After the surface reaction, the electrodes were washed for $5 \mathrm{~min}$ each in $20 \mathrm{mM}$ PB (with $0.1 \%$ Tween-20), $20 \mathrm{mM}$ PB (with $150 \mathrm{mM} \mathrm{NaCl}$ ) and $20 \mathrm{mM} \mathrm{PB}$ on a shaker, and then dried with nitrogen. Tris- $\mathrm{HCl}(\mathrm{pH} 8.5,1.0 \mathrm{M})$ was used to block the residual reacting sites on the electrodes. The reaction was kept for $30 \mathrm{~min}$ at room temperature.

\subsection{Assay of OGT activity and inhibition}

OGT activity assay was performed according to the following procedure. Firstly, the reaction mixture containing $25 \mathrm{mM}$ Tris- $\mathrm{HCl}$ (pH 7.4), $10 \mathrm{mM} \mathrm{CaCl}_{2}, 0.05 \%$ Tween-20, 0.05\% NP-40, $50 \mu \mathrm{M}$ UDPGlcNAc, $0.1 \mathrm{U} \mathrm{mL}^{-1}$ alkaline phosphatase and OGT in a total volume of $10 \mu \mathrm{L}$ was deposited onto the surface of the peptide-modified electrode and incubated in a moisturized container at $37^{\circ} \mathrm{C}$ for $45 \mathrm{~min}$. Alkaline phosphatase was used to complete the hydrolysis of UDP-GlcNAc into GlcNAc. For the inhibition experiment, varying concentration of inhibitor was included in the reaction mixture of OGT. Then, the proteinase $\mathrm{K}$ solution containing $10 \mathrm{mM}$ Tris- $\mathrm{HCl}(\mathrm{pH} 7.4), 1 \mathrm{mM}$ $\mathrm{Ca}\left(\mathrm{CH}_{3} \mathrm{COO}\right)_{2}$ was coated onto the surface of the electrode and incubated in a moisturized container at $37^{\circ} \mathrm{C}$ for $60 \mathrm{~min}$. After washing in $\mathrm{PB}$, cyclic voltammograms (CVs) were measured in $3 \mu \mathrm{M}$ Os(bpy) ${ }_{3}{ }^{2+} / 20 \mathrm{mM}$ PB (pH 7.4).

\subsection{X-ray photoelectron spectroscopy (XPS) characterization of $N$ element}

X-ray photoelectron spectrometer (XPS) measurements were made on a VG ESCALAB MkII spectrometer from Thermo VG Scientific (East Grinstead, West Sussex, UK) with a Mg Ka X-ray source $(1253.6 \mathrm{eV}$ photons). All binding energies (BEs) were referenced to the neutral $\mathrm{C} 1 \mathrm{~s}$ peak at $284.6 \mathrm{eV}$.

\section{Results and discussion}

\subsection{The response mechanism of label-free electrochemical biosensor}

Tyrosine is chosen as the intrinsic signal reporter due to its lowest oxidation potential compared with other redox-active amino acid residues. Besides, the oxidation signal of tyrosine can be amplified when an electron mediator with appropriate oxidation potential is employed. A signal-enhancing system based on the electrocatalytic oxidation of tyrosine on ITO electrode, using osmium polypyridine complex as a redox mediator, has been developed (Fecenko et al., 2006; Wei et al., 2012). Os(bpy) ${ }_{3}{ }^{2+}$ is chemically stable and shows reversible electrochemical response on the ITO electrode. Its oxidation potential is high enough to oxidize tyrosine. The mechanism of signal enhancement involves electrochemical oxidation of the mediator Os(bpy $)_{3}{ }^{2+}$ to Os(bpy $)_{3}{ }^{3+}$ on the ITO electrode, followed by a chemical reaction between Os(bpy $)_{3}{ }^{3+}$ and tyrosine to produce Os(bpy $)_{3}{ }^{2+}$ and oxidized tyrosine. ITO was selected as the working electrode because it is chemically inert and has a wide potential window (up to $2 \mathrm{~V}$ ), and the background current or direct tyrosine oxidation on ITO is very low. Its surface is relatively hydrophilic and therefore unfavorable for nonspecific protein adsorption. In addition, the hydroxyl groups on the ITO surface allow surface modification through silanization and subsequent protein immobilization. The detection principle for OGT activity is illustrated conceptually in Scheme 1. A peptide substrate with tyrosine residues labeled at $\mathrm{C}$-terminal contained a unique protease site adjacent to the glycosylation site. Os(bpy) ${ }_{3}{ }^{2+}$-mediated tyrosine oxidation current was used as the signal reporter. Proteinase K, as a specific serine protease, was introduced. The predominant site of cleavage is the peptide bond adjacent to the carboxyl group of aliphatic and aromatic amino acids with blocked $\alpha$-amino groups (Ebeling et al., 1974). Before the peptide glycosylation, proteinase K could easily cleave the peptide into two pieces. After washing the electrode, the part containing the tyrosine residues was removed from the surface of the electrode and thus resulted in loss of electrochemical signal. By contrast, the glycosylation of peptide could protect it from the cleavage of proteinase $\mathrm{K}$, thus leading to enhancement of signal in Os(bpy $)_{3}{ }^{2+}$ solution.

\subsection{Peptide immobilization and characterization}

According to the signal-enhancing system that relies on the electrocatalytic oxidation of tyrosine mediated by osmium bipyridine, our group have carried out some related works for the analysis of protein functions, including the monitoring of protein-conformation change (Guo et al., 2006), detection of protein oxidative damage (Qu et al., 2011) and protein phosphorylation (Yang et al., 2011). Now, in our work, peptide, as the substrate of OGT, was covalently immobilized on GPTMS-modified ITO electrode. X-ray photoelectron spectroscopy (XPS), as a unique surface-sensitive technique for chemical analysis, was used to characterize the assembling processes of peptide on ITO electrode. Fig. S1 showed typical XPS spectra of peptide films and the change in intensity of XPS peak before and after the peptide assembly on the GPTMS-modified ITO (Fig. S1 in the Supplementary material). A clear XPS peak of $\mathrm{N}_{1 \mathrm{~s}}$ at $399.5 \mathrm{eV}$ is assigned to nitrogen atoms, present in the amide bonds in the peptide chain and amino acid side chains. While, there was no such peak for bare or GPTMS-modified ITO. And then, a series of experiments were conducted by measurement of the tyrosine electrochemical signal. The oxidation current of peptide on ITO electrode was low even with a number of oxidizable tyrosine residues. As shown in Fig. 1, in PB solution, there was a very weak oxidation peak at about $0.75 \mathrm{~V}$ on peptide-immobilized ITO

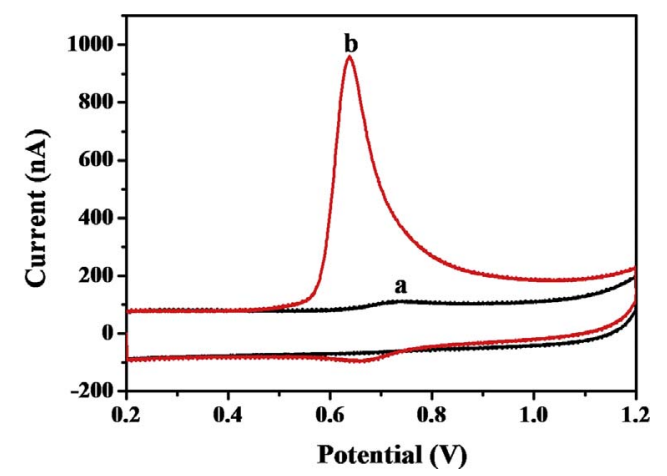

Fig. 1. CVs obtained with peptide-modified electrode in (a) $20 \mathrm{mM}$ PB solution and (b) $3 \mu \mathrm{M} \mathrm{Os}(\mathrm{bpy})_{3}{ }^{2+}$ solution. Supporting electrolyte: $20 \mathrm{mM}$ PB solution, $\mathrm{pH}$ 7.4. Scan rate $30 \mathrm{mV} \mathrm{s}^{-1}$. The peptide incubation concentration was $0.3 \mathrm{mg} \mathrm{mL}^{-1}$. 
electrode, resulting from the oxidation reaction of tyrosine residues in the peptide. However, in $\mathrm{Os}(\mathrm{bpy})_{3} \mathrm{Cl}_{2}$ solution, an enhanced oxidation current of tyrosine residues from peptide-immobilized ITO electrode was observed, which was almost 8-fold higher than that in PB solution. It demonstrated that the addition of $\mathrm{Os}(\mathrm{bpy})_{3}{ }^{2+}$ could efficiently catalyze the oxidation of tyrosine residues in peptide and produced high catalytic current. Moreover, the oxidation potential on peptideimmobilized ITO electrode in Os(bpy) ${ }_{3}{ }^{2+}$ solution $(\sim 0.64 \mathrm{~V})$ shifted more negatively than that in $\mathrm{PB}$ solution $(\sim 0.75 \mathrm{~V})$. As stated above, Os(bpy $)_{3}{ }^{2+}$ complex is redox active. The oxidation potential of Os(bpy) ${ }_{3}{ }^{2+}$ (about $\sim 0.70 \mathrm{~V}$ ) is very close to that of tyrosine (about $\sim 0.75 \mathrm{~V}$ ). Therefore, Os(bpy) ${ }_{3}{ }^{2+}$ can be used as an electron mediator for the electron transfer between tyrosine and electrode. The introduction of Os(bpy $)_{3}{ }^{2+}$ accelerated the electron transfer process between tyrosine residues in peptide and the surface of electrode. It made tyrosine oxidize at lower potential easily and resulted in the shift of peak potential towards less positive potential. The peak-shaped catalytic voltammogram was ascribed to depletion of the limited amounts of peptides immobilized on the ITO electrode. Also, the immobilization of peptide onto GPTMS-modified ITO electrode was investigated as a function of peptide concentration. Initially the electrochemical current was enhanced with the increase of peptide concentration, and then leveled off at $0.3 \mathrm{mg} \mathrm{mL}^{-1}$ and above (Fig. 2). It suggested that the electrochemical current was closely associated with the amount of peptide immobilized on ITO electrode. The optimal peptide concentration was chosen to be $0.3 \mathrm{mg} \mathrm{mL}^{-1}$.

\subsection{CVs measurements of peptide proteolysis}

On the basis of the optimal condition, peptide-immobilized ITO electrode was incubated with different concentration of proteinase $\mathrm{K}$. Fig. 3 showed the dependence of the current response on proteinase $\mathrm{K}$ concentration with peptide-immobilized electrode in $20 \mathrm{mM} \mathrm{PB}(\mathrm{pH}$ 7.4) containing $3 \mu \mathrm{M}$ Os(bpy $)_{3}{ }^{2+}$ solution. When the concentration of proteinase $\mathrm{K}$ increased, the currents obtained from the electro-catalyzed tyrosine oxidation decreased accordingly. It reached a saturation value once the concentration of proteinase $\mathrm{K}$ was above $50 \mathrm{ng} \mathrm{mL} \mathrm{m}^{-1}$, indicating that proteinase $\mathrm{K}$ could efficiently cleave all the unglycosylated peptide and thus resulted in the decrease of the available tyrosine residues in peptide on ITO electrode. The time of peptide cleaved by proteinase $\mathrm{K}$ was optimized to determine whether the peptide was allowed enough time to react with $50 \mathrm{ng} \mathrm{mL}^{-1}$ proteinase $\mathrm{K}$. As the proteolysis time was increased, the electro-catalyzed oxidation signal of the available tyrosine decreased and then reached a plateau after $60 \mathrm{~min}$ (Fig. S2). Hence, $60 \mathrm{~min}$ was selected as optimal proteolysis time.

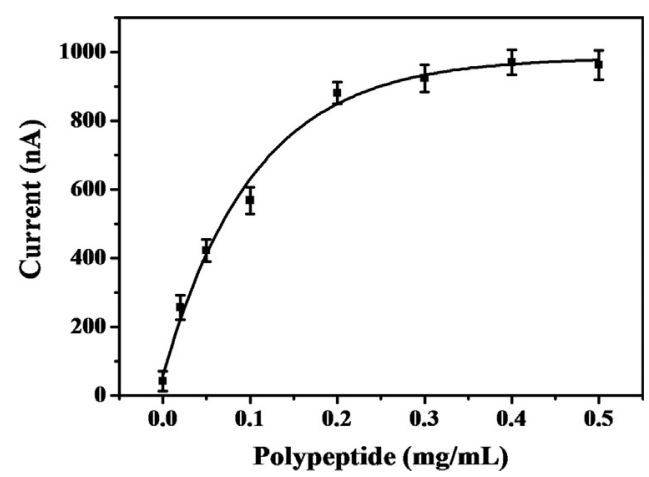

Fig. 2. Dependence of current intensity on peptide incubation concentration. The peptide concentration was $0,0.02,0.05,0.1,0.2,0.3,0.4$, and $0.5 \mathrm{mg} \mathrm{mL}^{-1}$ respectively. Electrochemical measurements were carried out in $20 \mathrm{mM} \mathrm{PB}$ ( $\mathrm{pH} 7.4$ ) containing $3 \mu \mathrm{M}$ Os(bpy $)_{3}{ }^{2+}$. Scan rate: $30 \mathrm{mV} \mathrm{s}^{-1}$. Error bars indicated the standard deviation of measurements performed in triplicate $(n=3)$.

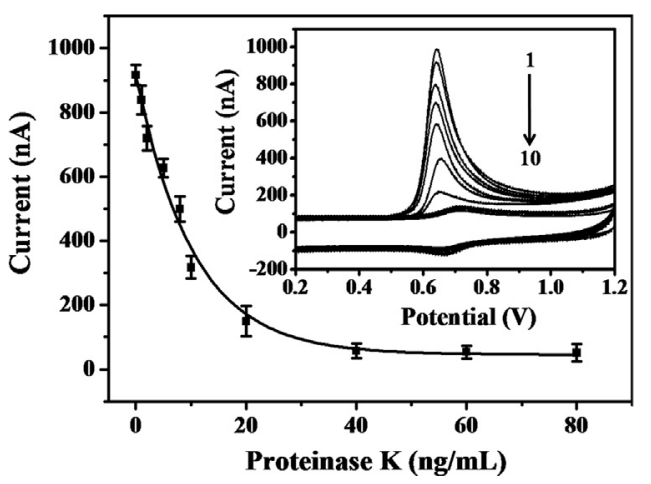

Fig. 3. Dependence of electrochemical signal on the concentration of proteinase $\mathrm{K}$. The concentration of proteinase $\mathrm{K}$ was $0,1,2,5,8,10,20,40,60$ and $80 \mathrm{ng} \mathrm{mL}^{-1}$ respectively. The incubation time was $60 \mathrm{~min}$. Electrochemical measurements were carried out in $20 \mathrm{mM}$ PB (pH 7.4) containing $3 \mu \mathrm{M} \mathrm{Os(bpy)}{ }_{3}{ }^{2+}$. Scan rate: $30 \mathrm{mV} \mathrm{s}^{-1}$. Error bars indicated the standard deviation of measurements performed in triplicate $(n=3)$. Inset: CVs of peptide-immobilized electrode as a function of the concentration of proteinase $\mathrm{K}$.

\subsection{Detection of OGT activity}

One eminent function of protein glycosylation can serve to protect the polypeptide chain from recognition by protease. The addition of oligosaccharides to polypeptide would protect adjacent cleavage sites from proteolysis. Then, suitable protease was added at concentration that cleaved the unglycosylated peptides to completion without affecting the glycosylated peptides. Accompanied with the introduction of OGT, the effect of glycosylated peptide on the current was investigated. As shown in Fig. 4, with the increase of OGT concentration, more and more peptides were glycosylated and protected themselves against subsequent cleavage by proteinase $\mathrm{K}$. Thus, more and more accessible tyrosine residues in peptide were electrochemically catalyzed by Os(bpy $)_{3}{ }^{2+}$ and led to higher electrochemical oxidation signals. It reached a saturation value once the concentration of OGT was above $200 \mathrm{nM}$ OGT. The dependence of the current response on the OGT concentration was presented in the inset of Fig. 4. Glycosylation time was optimized to determine whether the peptide was allowed enough time to react with $200 \mathrm{nM}$ OGT. As the glycosylation time was increased, the electro-catalyzed oxidation signal of tyrosine increased and then reached a plateau after $45 \mathrm{~min}$ (Fig. S3). Hence, 45 min was selected as optimal glycosylation time. In addition, ppGalNAc-T2 is a member of the O-GalNAc transferase subfamily, which catalyzes the transfer of UDP-GalNAc onto either serine or threonine residues of proteins trafficking through the Golgi compartment. It plays pivotal

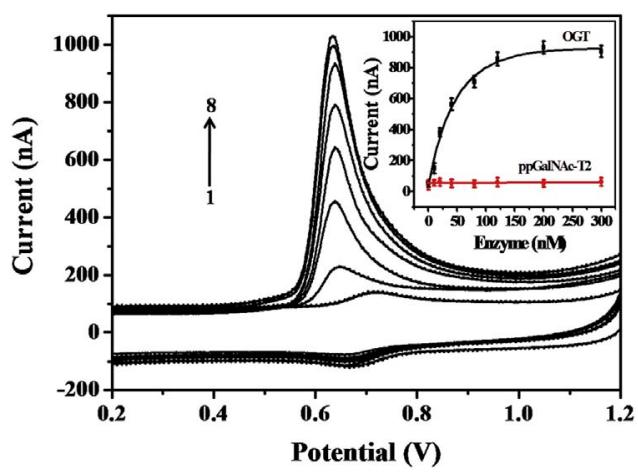

Fig. 4. CVs obtained with the modified electrode at several OGT concentrations (1) 0, (2) 10, (3) 20, (4) 40, (5) 80, (6) 120, (7) 200, (8) $300 \mathrm{nM}$ in $20 \mathrm{mM} \mathrm{PB}$ (pH 7.4) containing $3 \mu \mathrm{M} \mathrm{Os}(\mathrm{bpy})_{3}{ }^{2+}$ solution. The incubation time was $45 \mathrm{~min}$. Inset: Dependence of electro-catalyzed tyrosine oxidation signal on the concentration of OGT (Black line) or ppGalNAc-T2 (Red line). Error bars indicated the standard deviation of measurements performed in triplicate $(n=3)$. (For interpretation of the references to color in this figure legend, the reader is referred to the web version of this article.) 
roles in cytokine proteolytic processing, as the presence of O-linked sugar adjacent to a protease processing site is known to inhibit proteolysis and molecule inactivation. Therefore, to demonstrate the specificity of the O-GlcNAc glycosylation reactions, suitable O-GalNAc glycosylation solution containing ppGalNAc-T2 and UDP-GalNAc was incubated with peptide-immobilized ITO electrode. With the increase of ppGalNAc-T2 concentration, only electrochemical signal of Os(bpy) ${ }_{3}{ }^{2+}$ was observed and kept unchanged (Fig. 4 Inset), indicating that the peptides were not O-GalNAc glycosylated. It was attributed to the fact that the peptide immobilized on the ITO electrode was the substrate of OGT rather than that of ppGaINAc-T2. Therefore, it could not be catalyzed by ppGalNAc-T2 to transform into the glycosylated peptide, and subsequently cleaved by proteinase $\mathrm{K}$, and thus we could not detect the electro-catalyzed oxidation signals of tyrosine. These results demonstrated that the proposed biosensor can only be employed for the detection of OGT-catalyzed peptide O-GlcNAc glycosylation.

\subsection{Response characteristics of the electrochemical biosensor}

The performance of the electrochemical biosensor was evaluated. The reproducibility and repeatability of the biosensor were investigated with intra- and interassay precision. The intraassay precision of the biosensor was examined by measuring the same OGT activity using six electrodes from the same epoxysilane-activated ITO slice. The interassay precision was assessed by assaying the same level of OGT activity with six electrodes from different batches of epoxysilane-activated ITO slices. The relative standard deviation values obtained from $50 \mathrm{nM}$ OGT were found to be $6.9 \%$ and $8.8 \%$, respectively. Both the intra- and interassay of the biosensor enunciated acceptable reproducibility and repeatability.

\subsection{Inhibition assay of OGT activity}

Aberrant O-GlcNAcylation are associated with the onset and progression of some diseases. However, in most cases, a causal link between changes in protein glycosylation and the observed pathologies has not been clearly elucidated. The discovery of specific OGT inhibitors would be useful for probing how changes in glycosylation levels or glycan composition affect cells and tissues. Therefore, the biosensor was also applied to assess the inhibition of OGT in the presence of small molecule inhibitor. In the inhibition assay, the OGT activity was determined with OGT inhibitor at different concentration. Here, BZX (Gross et al., 2005) and alloxan (Dorfmueller et al., 2011), well-known as potent inhibitors of OGT, were employed. Fig. 5 showed the current responses obtained from the glycosylation reactions performed in the presence of BZX or alloxan. As the concentrations of inhibitors were increased, the electro-catalyzed oxidation currents of tyrosine gradually decreased. This suggested that the presence of inhibitor hampered the OGT-catalyzed glycosylation reaction and then more unglycosylated peptides became available for cleavage of proteinase K. Subsequently, less tyrosine residues in peptide on the surface of ITO electrode was electro-catalyzed by $\mathrm{Os}(\mathrm{bpy})_{3}{ }^{2+}$ and led to the decrease of the signal. Also, the inhibition times of inhibitors were optimized respectively. With increasing the inhibition times, the electro-catalyzed oxidation signal of tyrosine decreased, and then reached a plateau after 60 or $90 \mathrm{~min}$ (Fig. S4) respectively. Hence, optimal inhibition time was employed as $60 \mathrm{~min}$ for BZX or $90 \mathrm{~min}$ for alloxan. In addition, an uridine-based derivative, well-known as a selective inhibitor of ppGalNAc-T family, do not inhibit other mammalian glycosyltransferases or nucleotide sugar utilizing enzymes. It was also used to reassess the specificity of the biosensor. Concurring with expectations, the electro-catalyzed oxidation signals of tyrosine almost remained unchanged in the presence of ppGalNAc-T2 inhibitor with a concentration as high as $100 \mu \mathrm{M}$ (Fig. S5), showing attractive specificity of the biosensor to the OGT inhibitor profiling. Control of nuclear and cytoplasmic protein O-GlcNAcylation provides a means to influence numerous cellular events and the potential for management of various human diseases. To date, only a limited number of OGT inhibitors have been reported. The complexity, high cost, and limited versatility of classical OGT assays have been major obstacles in developing potent and selective OGT inhibitors. Indeed, the use of small-molecule OGT inhibitors has greatly assisted in the evolution of our understanding of O-GlcNAc's cellular roles. Our results indicate that the proposed electrochemical biosensor has a potential in screening the activity of the OGT inhibitors effectively. The new assay provides a complementary method to the use of antibodies, radioactive markers and labeled substrates.

\section{Conclusions}

An economic, convenient and label-free electrochemical biosensor for the assay of OGT activity and its inhibitors has been developed, based on the combination of protease-protection strategy with tyrosine electrocatalytic oxidation. Our proof-of-concept study involving the small-molecule inhibition on O-GlcNAcylation may have an important impact on disturbed effect research of environmental pollutant on protein glycosylation and elucidation of OGT biological role, because this strategy does not require complicated label procedures. The next challenge is the demonstration of the broader applicability or scope of the technique using more complex solution mixtures (such as cell extracts) and multiple enzymes for O-linked glycosylation. Our laboratory is currently working on adapting this technique to a microarray format, which will allow high-throughput screening of small molecule inhibition on OGT and toxicity of environmental contaminants.
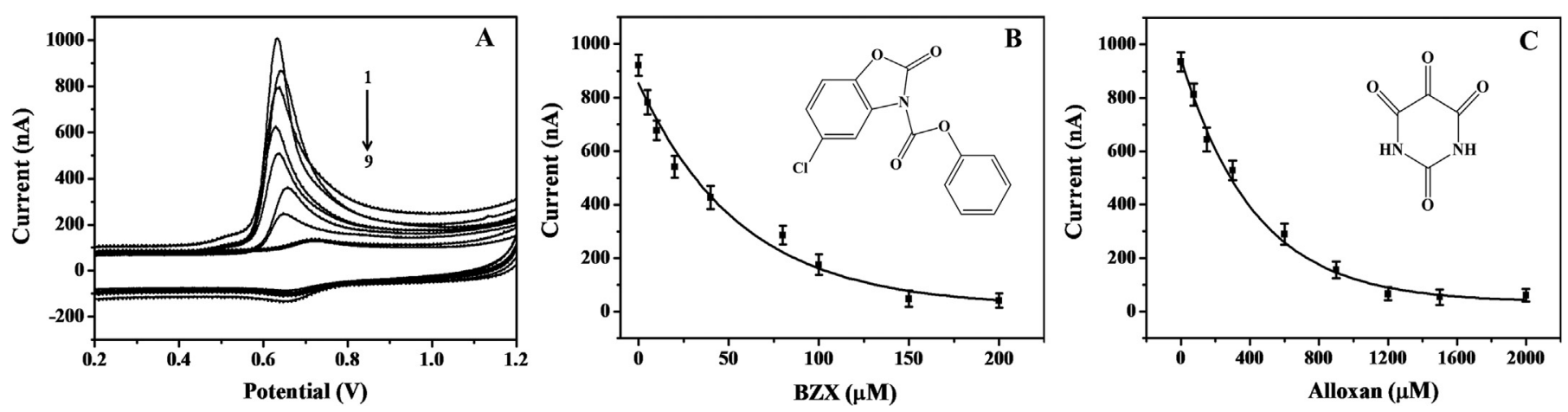

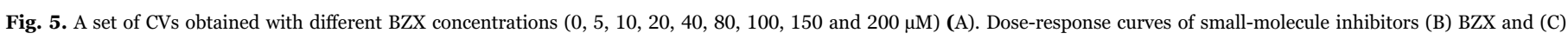

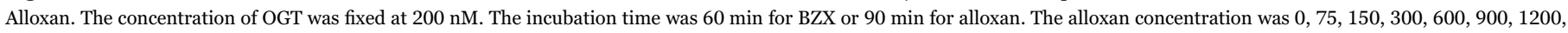
1500 and $2000 \mu \mathrm{M}$ respectively. Error bars indicated the standard deviation of measurements performed in triplicate (n=3). 


\section{Acknowledgments}

This work was supported by the Chinese Academy of Sciences (XDB14040100), National Basic Research Program of China (2015CB932003) and National Natural Science Foundation of China (Nos. 21377142, 21577163, 21321004, 91543203, 21375143, 21477146 and 21407168).

\section{Appendix A. Supporting information}

Supplementary data associated with this article can be found in the online version at doi:10.1016/j.bios.2017.04.009.

\section{References}

Caldwell, S.A., Jackson, S.R., Shahriari, K.S., Lynch, T.P., Sethi, G., Walker, S., Vosseller, K., Reginato, M.J., 2010. Oncogene 29, 2831-2842.

Cheng, X.G., Hart, G.W., 2001. J. Biol. Chem. 276, 10570-10575.

Chou, T.Y., Dang, C.V., Hart, G.W., 1995. Proc. Natl. Acad. Sci. USA 92, 4417-4421. Dorfmueller, H.C., Borodkin, V.S., Blair, D.E., Pathak, S., Navratilova, I., van Aalten, D.M.F., 2011. Amino Acids 40, 781-792.

Ebeling, W., Hennrich, N., Klockow, M., Metz, H., Orth, H.D., Lang, H., 1974. Eur. J. Biochem. 47, 91-97.

Fecenko, C.J., Meyer, T.J., Throp, H.H., 2006. J. Am. Chem. Soc. 128, 11020-11021. Gong, C.X., Liu, F., Grundke-Iqbal, I., Iqbal, K., 2005. J. Neural Transm. 112, 813-838. Gross, B.J., Kraybill, B.C., Walker, S., 2005. J. Am. Chem. Soc. 127, 14588-14589.

Gross, B.J., Swoboda, J.G., Walker, S., 2008. J. Am. Chem. Soc. 130, 440-441.

Guo, L.H., Qu, N., 2006. Anal. Chem. 78, 6275-6278.
Hamann, T.W., Gstrein, F., Brunschwig, B.S., Lewis, N.S., 2005. J. Am. Chem. Soc. 127, 7815-7824.

Hart, G.W., Housley, M.P., Slawson, C., 2007. Nature 446, 1017-1022.

Leavy, T.M., Bertozzi, C.R., 2007. Bioorg. Med. Chem. Lett. 17, 3851-3854.

Lefebvre, T., Pinte, S., Guérardel, C., Deltour, S., Martin-Soudant, N., Slomianny, M.C., Michalski, J.C., Leprince, D., 2004. Eur. J. Biochem. 271, 3843-3854.

Lehman, D.M., Fu, D.J., Freeman, A.B., Hunt, K.J., Leach, R.J., Johnson-pais, T., Hamlington, J., Dyer, T.D., Arya, R., Abboud, H., 2005. Diabetes 54, 1214-1221.

Levine, Z.G., Walker, S., 2016. Annu. Rev. Biochem. 85, 631-657.

Lubas, W.A., Hanover, J.A., 2000. J. Biol. Chem. 275, 10983-10988.

Qu, N., Guo, L.H., Zhu, B.Z., 2011. Biosens. Bioelectron. 26, 2292-2296.

Sayat, R., Leber, B., Grubac, V., Wiltshire, L., Persad, S., 2008. Exp. Cell Res. 314, 2774-2787.

Singh, J.P., Zhang, K.S., Wu, J., Yang, X.Y., 2015. Cancer Lett. 356, 244-250.

Slawson, C., Hart, G.W., 2011. Nat. Rev. Cancer 11, 678-684.

Slawson, C., Zachara, N.E., Vosseller, K., Cheung, W.D., Lane, M.D., Hart, G.W., 2005. J. Biol. Chem. 280, 32944-32956.

Vocadlo, D.J., 2012. Curr. Opin. Chem. Biol. 16, 488-497.

Wei, M.Y., Guo, L.H., Famouri, P., 2012. TRAC-Trends Anal. Chem. 39, 130-148.

Wells, L., Slawson, C., Hart, G.W., 2011. Amino Acids 40, 877-883.

Wu, Z.L., Ethen, C.M., Prather, B., Machacek, M., Jiang, W.P., 2011. Glycobiology 21, 727-733.

Yang, X.Y., Zhang, F.X., Kudlow, J.E., 2002. Cell 110, 69-80.

Yang, Y., Guo, L.H., Qu, N., Wei, M.Y., Zhao, L.X., Wan, B., 2011. Biosens. Bioelectron. 28, 284-290.

Yuzwa, S.A., Vocadlo, D.J., 2014. Chem. Soc. Rev. 43, 6839-6858.

Zachara, N.E., O’Donnell, N., Cheung, W.D., Mercer, J.J., Marth, J.D., Hart, G.W., 2004. J. Biol. Chem. 279, 30133-30142.

Zeidan, Q., Hart, G.W., 2010. J. Cell Sci. 123, 13-22.

Zhang, F.X., Su, K.H., Yang, X.Y., Bowe, D.B., Paterson, A.J., Kudlow, J.E., 2003. Cell $115,715-725$. 